Article

\title{
Sustainability Tensions in Supply Chains: A Case Study of Paradoxes and Their Management
}

\author{
Carolin Brix-Asala *, Anne-Kristin Geisbüsch, Philipp Christopher Sauer ${ }^{(\mathbb{D}}$, Patrick Schöpflin \\ and Axel Zehendner \\ Supply Chain Management, University of Kassel, Kleine Rosenstraße 1-3, 34109 Kassel, Germany; \\ ak.geisbuesch@gmail.com (A.-K.G.); philipp.sauer@uni-kassel.de (P.C.S.); patrick.schoepflin@gmx.de (P.S.); \\ axel.zehendner@gmail.com (A.Z.) \\ * Correspondence: Carolin.Brix-Asala@uni-kassel.de
}

Received: 29 December 2017; Accepted: 1 February 2018; Published: 6 February 2018

\begin{abstract}
The comprehensive coverage of sustainability issues in a supply chain incurs goal conflicts-i.e., sustainability tensions-and is often limited by market characteristics, such as the availability of sustainable materials and services. While the mainstream business is prioritizing economic goals, a number of entrepreneurs are trying to move forward to more sustainable business practices for their own company and their supply chain. Fairphone represents such a case in the electronics industry, which is openly communicating its sustainability efforts and shortcomings. This communication is content-analyzed in this study by applying the theoretical lenses of paradox sustainability tensions and sustainable supply chain management. Findings of this analysis reveal the limitation of sustainability efforts by supply side characteristics, while Fairphone is innovatively using the demand side of its supply chain to drive sustainability. The resulting tensions among both sides are addressed via pro-active and direct supplier and stakeholder engagement by Fairphone at their suppliers' mines and factories. The systematic identification of tensions and practices by which they are addressed is adding to our understanding of sustainability practices and goal conflicts in supply chains.
\end{abstract}

Keywords: sustainability tensions; paradox theory; sustainable supply chain management; Fairphone; mineral resources

\section{Introduction}

Since 2014, there have been more mobile devices than human beings on earth and numbers are still rising [1]. The production of the devices and sourcing of the required raw materials incurs severe sustainability challenges, such as the use of water, energy and chemicals, the affection of ecosystems and landscapes as well as the emission of flue gases and wastes [2-4]. Moreover, social issues, like insufficient wages, long working hours, unpaid overtime and physical punishment, have been reported in mobile phone production facilities located in China and India [5-7]. All these issues are further multiplied by the low durability of electronic devices [8] and the poorly used recycling potential in the sector [2,9]. Still, all these issues are largely disregarded by mobile phone users, who rather focus on the phones' performances, brands and prices [10].

Leading multi-national companies largely assume the enhancement of the sustainability in the production of minerals and related products to be not cost-effective [11-13]. In fact, such raw materials are sourced from large commodity exchanges, like the London Metal exchange, which reported a trading volume of $\$ 10.3$ trillion in 2016 [14]. This kind of procurement minimizes cost, but also causes a lack of transparency due to the loss of information of the supply source of metals [13]. In turn, this lack of supplier information hinders the evaluation and management of the just-mentioned sustainability challenges in the sector [13]. In effect, the competing demands between cost optimization 
and socio-environmental sustainability are a major sustainability tension which the smartphone industry currently faces [10-12].

Since 2010, this tension between the socio-environmental and economic dimensions of sustainability has been challenged by Fairphone-a niche brand focusing on sustainably produced smart phones. The company's vision "to create positive social and environmental impact from the beginning to the end of a phone's life cycle" [15] contrasts the focus on the business case, which has been, to date, the dominant goal in the industry [11,12]. This study frames the tensions among the socio-environmental and economic dimensions of sustainability as a paradox, which consists of "contradictory yet interrelated elements that exist simultaneously and persist over time" [16] (p. 382). The paradox perspective sees environmental and social sustainability as standalone ends, which do not necessarily have to contribute to the economic success of an organization $[16,17]$. This perspective seems to be a good fit for analyzing the case of Fairphone, as it covers the company's long-term objectives of creating environmental and social prosperity. Furthermore, it is an interesting lens as it widens the perspective on corporate sustainability and especially, the management of tensions, which would be much more limited when evaluated under a profit maximization logic [17].

In order to better understand the paradox sustainability tensions arising along the largely outsourced smart phone production [10], the study adopts a sustainable supply chain management (SSCM) perspective $[13,18,19]$. It helps to derive the practices for addressing the tensions and to understand the uncertainties and risks which originate from supply, demand and technological uncertainty in electronic supply chains (SCs) $[20,21]$. Literature on SSCM illustrates the most common practices and strategies which focal companies can adopt to integrate environmental, social and economic goals in their SC. Thus, it is a useful lens for researching the complexity of SC, related to the sustainability of mineral resources and related products $[13,22,23]$.

As a result of the previously mentioned arguments, the following research questions (RQs) were defined for the study:

RQ1: What kind of paradox sustainability tensions can be identified in electronic supply chains?

RQ2: Which practices are used by companies to address paradox sustainability tensions in electronic supply chains?

To achieve the two research aims, a case study on Fairphone was conducted. Fairphone was chosen as it aims to produce smartphones as sustainably as possible and thus, contradicts common market logics. Since Fairphone openly communicates about sustainability challenges and problems within their SC, the company is seen as a pioneer in this regard and thus as a unique and revelatory case [24], which offers managerial as well as research direction.

In effect, the study contributions are three-fold. First, it provides empirical insight into the sustainability tensions which Fairphone faces, and how they are addressed by means of SSCM practices. This contribution answers the call to systematically delineate the sustainability tensions relevant to praxis, and to propose possible solutions in order to build holistic approaches to current sustainability challenges [25]. Adopting SSCM to frame the solution approaches promises rich insight into inter-organizational tensions. In turn, this adoption represents the second contribution of extending the SSCM debate, by adding empirical insight into the complex interplay of SC partners, SC sustainability and SC performance. This has, to date, mostly been investigated from a win-win or trade-off perspective [26-28], which has recently been criticized and complemented by calls to adopt a paradox lens [29]. As this study shows, an application of the paradox lens can help to dive deeper into the fields of stakeholder risks in SSCM as well as social sustainability in SCs, which have both been under-researched to date [30,31]. The third contribution is that the adoption of social and environmental value, as a standalone goal can change classical supply and demand risks, such as the procurement of conflict minerals, into a value proposition. Fairphone's pro-active engagement in risks which affect raw material extraction as well as the easy reparability of their phones are business practices which significantly differ from those of other electronic companies. These actions incur extra costs and cannibalize repair income, but are considered highly valued by the company's stakeholders and customers. 
The remainder of the paper is structured as follows: It introduces the theoretical background of paradox tensions as well as SSCM and its practices in Section 2. Building on that, a definition of paradox sustainability tensions is derived which serves as the basis for the case study. The methodology is outlined in Section 3, before the identified paradox tensions and practices are related to theory in Section 4. Finally, the discussion in Section 5 relates to prior work of scholars, before a short conclusion is drawn.

\section{Theoretical Background}

\subsection{Paradox Sustainability Tensions}

\subsubsection{Differentiating Win-Win, Trade-Off, Integrative, and Paradox Lenses}

Van der Byl and Slawinski [25] analyzed how tensions are examined in corporate sustainability research. They exposed the four different lenses of win-win, trade-off, integrative, and paradox that are used for analyzing tensions. According to the win-win approach, tensions are circumvented by looking for opportunities to align environmental and/or social goals with economic goals. The approach is based on the assumption that an improvement in one dimension of sustainability also improves at least one of the other two dimensions, or at least does not diminish them. It focuses on examining how companies gain financial performance through increasing their sustainability performance. Contrastingly, the trade-off approach recognizes that conflicts between the sustainability goals occur and cannot be achieved simultaneously. To eliminate the tension between these contradictory goals, companies must choose one goal over another. Research with an integrative view does not prioritize any of the three dimensions of sustainability. Instead it assumes that the environmental, social and economic goals can be balanced, and it seeks to reach the three pillars holistically, without weighting one over another. While an integrative view balances the three pillars of sustainability, a view with a paradox lens attempts to understand the tensions, their nature and how actors deal with them [25]. Paradoxes can be defined "as contradictory yet interrelated elements that exist simultaneously and persist over time" [16] (p. 382). Regarding sustainability, this definition can be transferred to the three dimensions. If each of them is considered individually, they seem logical, but when juxtaposed, they are rather of a contradictory interplay. According to the paradox lens, firms and actors have to embrace the tensions, instead of avoiding or resisting occurring tensions between the three sustainability goals. After the first step of identifying and understanding the tensions, actors should accept them, by admitting the coexistence of contradictory elements $[16,32]$. The contradiction remains central to the paradox approach and therefore differs from a "traded-off" situation, where the contradiction is eliminated by the decision of one goal over another. By using resolution strategies of temporal or spatial separation/splitting and synthesis/integration, actors aim to transform the situation so that interrelating demands can be simultaneously pursued without actually eliminating the tension. Thus, continuous efforts as well as cyclical and iterate responses are required to meet contradictory demands and to create long-term sustainability performance [16,25,32]. Based on this, three criteria for the definition of a paradox tension can be derived:

1. Actors embrace the tensions between goals, rather than resisting or avoiding tensions;

2. Actors attend to competing and interrelated demands simultaneously;

3. Paradoxes are dynamic demands which can be managed only by continuous cyclical responses in the form of practices.

Based on these criteria, the next two sub-sections look into tensions in organizational research and sustainability tensions in SC research in order to understand their nature, before Section 2.2 defines the practices that can be used for responding to the tensions. 


\subsubsection{Tensions in Organizational Research}

The organizational research around paradox tensions seeks to explore both the interrelations between competing demands and how organizations can comply with the need for dealing with them simultaneously [16].

Smith and Lewis [16] developed a framework that differentiates organizational paradox tensions into four categories, which all represent elements and core activities of organizations. Tensions can appear between, as well as within, the categories of Learning (knowledge), Belonging (identity/interpersonal relationships), Organizing (processes), and Performing (goals) [16].

When organizational leaders must determine an action's time horizon, they face learning paradoxes. These paradoxes occur during change and adjustment processes and the appearance of innovations. They are inherent in the objective of companies to build upon experiences and capabilities of the past through continuous change, as well as to destroy the old and start radical, creative destruction processes. Belonging paradoxes-also called tensions of identity-arise when individuality and homogeneity of individuals and groups are simultaneously striven for. On an organizational level, belonging paradoxes can surface if competing values, roles, and memberships exist simultaneously within a company. They emerge because of the unavoidable division of tasks in companies. Organizing paradoxes appear when a company decides how it is going to operate and when competing processes to achieve a specific outcome exist. Paradoxes of this kind include, for example, tensions between collaboration and competition, which both strive to achieve a competitive advantage, but can also hinder each other. By defining what an organization is going to do, performing paradoxes arise from competing strategies and goals to meet the various demands of internal and external stakeholders. For instance, paradoxes of this kind emerge when the financial goals, for example of shareholders, collide with the social or environmental expectations of other stakeholders.

Tensions arise not only within one category, but also between them [16]. Paradoxes between Learning and Performing reflect the conflict between ensuring the current company's success and the need for building up capabilities for the future. Tensions between Learning and Belonging appear when there is a need for change, and simultaneously, there is the wish to hold on a developed sense of purpose and self. Paradoxical tensions between Learning and Organizing emerge when organizations want to be agile and open to change, to be flexible in their routines. Simultaneously, these companies also seek for efficiency and focus. Tensions between Organizing and Performing are the result of conflicts between means and ends, as well as processes and outcomes of a company. For instance, the objectives to meet demands of employees and customers or to seek high commitment and high performance are often contradictory. Paradoxes between Belonging and Performing appear when the identification and conviction of employees conflict with company goals and occupational demands. The case of paradox tensions between Belonging and Organizing appear as an interplay of the individual and the aggregate. While organizations are most successful if their individuals are committed and willing to contribute to the whole, working in organizations also requires collective actions and thus, the subjection of individual convictions to some extent [16].

Due to the fact that sustainability issues have no simple solutions and are embedded in complex systems, solving them requires creativity and a paradox in thinking of how to deal with them [25]. An SC can be understood as a complex system. Diverse entities, processes and resources as well as a huge amount of interactions, inter-dependencies and interplays among them result in the need for dynamical responses to tensions [33].

\subsubsection{Sustainability Tensions in Supply Chain Research}

Screening the literature for sustainability tensions and SCs, a range of tensions are discussed either as purely conceptual in SSCM or its functions [29,34], in industry specific case studies [35,36] or in multi-industry studies on an individual level $[37,38]$. With regard to this study, we see overlaps in the reverse exchange of electronic products [36], the call for a systems perspective [34] and the supply chain position paradox [37]. The underlying study design thus takes up the most recent calls and research directions in corporate sustainability tensions research. 
Besides the currently dominating normative-theoretical literature on sustainability tensions, Van der Byl and Slawinski [25] called for more empirical investigation to understand how firms handle sustainability tensions by balancing conflicting demands instead of avoiding them. Currently, available papers on sustainability tensions focus on sustainability reporting practices and the link to environmental performance [39], sustainability communication in luxury goods companies [40], the poverty- $\mathrm{CO}_{2}$ reductions paradox on a national level [41] as well as multi-industry case studies at the intersection of companies and public policy [42]. The latter paper [42] also underlines the crucial role that public policy can play in foregrounding sustainability tensions, which is an important insight in the highly regulated mining industry. No relevant overlap with our focus on tensions in the electronic industry was found.

The examined literature on paradox tensions thus underlines three main insights. First, there is still the need for more explorative studies in order to strengthen the theory base. Second, multiple industries have been investigated, which delivered distinctively different tensions. Thus, there is the need to further broaden the scope of industries by reviewing the electronic industry, which, until now, has received only marginal attention in paradox sustainability tensions research. Third, current literature focuses on intra-organizational tensions, rather than the inter-organizational SC view. However, extending the focus to the inter-organizational level enables (1) the investigation of buyer-supplier relations which often shape the sustainability strategies of the supplier [19]; (2) gaining deeper insights into the stakeholder pressures driving SSCM [19,30]; and (3) adding insight into the so far under-researched social sustainability in SCs $[19,31]$.

Due to these gaps in the literature, the paper adopts a paradox lens to investigate the tensions in electronic SCs. These tensions need to be addressed by the single companies and the total SC [34,37]. That is why SSCM and its practices are elucidated in the following.

\subsection{Sustainable Supply Chain Management and Its Practices}

Important aspects of SCM are efficiency improvements, reduction of uncertainties and waste avoidance, since they increase the economic performance of the SC and its members $[20,43]$. These insights have been extended by research on Green SCM [43-45] and the later inclusion of the social dimension, which resulted in the SSCM approach $[18,19]$. This extension of the SCM theory is often operationalized by the implementation of Elkington's [46] triple bottom line (TBL) approach, which "calls for equal consideration of all three pillars of sustainability, namely, economy, ecology and society" [18] (p. 323). SSCM can thus be defined as "the management of material, information and capital flows as well as cooperation among companies along the SC while taking goals from all three dimensions of sustainable development, i.e., economic, environmental and social, into account which are derived from customer and stakeholder requirements" [19] (p. 1700).

For the analysis of the case company's approach for managing the paradoxes, the SSCM framework by Beske and Seuring [18] is adopted, which identifies practices and strategies related to SSCM. These are structured into five main categories: Orientation, Continuity, Collaboration, Risk Management and Pro-Activity. The categories are briefly outlined as they build the theoretical frame for answering RQ2.

Beske and Seuring [18] see the strategic Orientation of all SC members towards the TBL and SCM as an essential antecedent for the successful implementation of SSCM. Continuity and Collaboration practices shape the structure of the SC and define how the different members work together. They thus have an ultimate influence on the SC performance outcomes. An example of a Continuity practice of the focal firm is the investment in Long-Term Relationships with key suppliers, to create similar structures as well as common values and goals. Furthermore, Development of Supply Chain Partners, e.g., through education and training, can improve their overall capabilities and enhance the (sustainable) SC performance. A suitable Selection of Supply Chain Partners is important, as the overall SC performance depends on its weakest link and is thus especially important in the electronic SC with its high number of members [18,47]. As a result of seeking Long-Term Relationships, trust between SC partners can 
evolve and facilitate knowledge and information sharing. Likewise, Collaboration practices, such as Enhanced Communication, drive inter-organizational learning through long-term orientation and trust. Further Collaboration practices are Joint Development of products, Logistical Integration of SC partners in planning and forecasting processes, and Technological Integration. Implementing SSCM practices induces risks in the SC which are addressed in the Risk Management category. To reduce the risk of reputation loss due to social and environmental failures, companies frequently adopt Standards and Certifications, like ISO 14001, or define codes of conduct that demand a certain sustainability performance from their suppliers [19]. Furthermore, the cooperation with Pressure Groups, like Non-Governmental Organizations (NGOs), can help to exchange knowledge about possible risks in the SC and thereby support the gain of more legitimacy. Standards can also enhance the practice of Selective Monitoring, where sustainability performance measurement systems are implemented to assess the suppliers' actions in formal or informal ways. The Pro-Activity category aims at the continuous search for sustainability performance improvements, potentially leading to competitive advantages and first-mover advantages. The search for superior sustainability fosters Innovations of sustainable products and services within the SC. A Life Cycle Assessment (LCA) facilitates the implementation of recycling and reusing. Stakeholder Management, in which different SC members, like suppliers and customers, are involved can also facilitate the development phase and fuel Learning processes, which can encompass a change in the SCs culture and structure based on the lessons learned.

Sauer and Seuring [13] extended the framework of Beske and Seuring [18] with specific SC practices aiming to improve the sustainability of mineral chains. Based on a literature review, the authors propose the addition of Governmental Interventions as a new category of the SSCM framework, since the government is capable to influence-directly and indirectly-the sustainability of mineral chains. Furthermore, the authors expand two of the original categories-Risk Management and Pro-Activity - with mineral-specific practices.

The framework by Beske and Seuring [18] also proved its applicability in researching complex SSCM topics with regard to base of the pyramid research [48]. Consequently, this framework is seen as a sound basis for this case study, which is characterized in the next section.

\section{Methodology}

\subsection{Case Study}

A case study examines a contemporary topic or phenomenon within its real-life setting to understand its dynamics in this context. Case study research is especially reasonable for an analysis in which the boundaries between the phenomenon and its context are indistinct. The research approach of such an in-depth inquiry can help to identify what and why something is happening. Moreover, it enables researchers to understand the effects of a situation and points out implications for action $[24,49]$.

The underlying case study analyzes the single case of Fairphone. Fairphone represents, in the electronic industry, a unique company as it tries to deal with tensions that occur with the production of smartphones instead of avoiding them. As such, this case study represents a unique and revelatory case [24], which provides novel insight into the management of sustainability tensions in a complex SC. For conducting the case study, this paper uses a qualitative approach to identify the paradox sustainability tensions. This approach is described in detail in Section 3.3 "Data analysis". Moreover, the SSCM practices used to address the tensions are analyzed. This analysis is furthermore structured against the generic structure of a mineral SC [13], as outlined in Figure 1.

Figure 1 covers the entire product life cycle of a smart phone including the forward and reverse SC. Additionally, the typical division of a mineral SC into upstream and downstream SC is adopted. This enables the investigation of the close relationship between the electronic industry (i.e., downstream SC), its dependence on raw material suppliers in the upstream SC and the role of the global mineral markets, which represent a critical link among the SC parts at which product related 
information is often lost [13]. As such, the depicted SC represents a dynamic and complex system (see also [22,50]) in which tensions arise and need to be managed. In particular, the price driven procurement of raw materials has led to the outsourcing of a large share of upstream activities to low cost countries, in which poor working conditions, forced and child labor as well as low environmental standards represent a major sustainability uncertainty and challenge $[13,23,50,51]$. This represents a major supply uncertainty for Fairphone, as its value proposition is enhanced sustainability in its SC. The company thus has to take leadership of its SC and can therefore be understood as the downstream focal firm in the SC. To better understand the role of Fairphone in the Smartphone industry, the company is introduced in the next section.

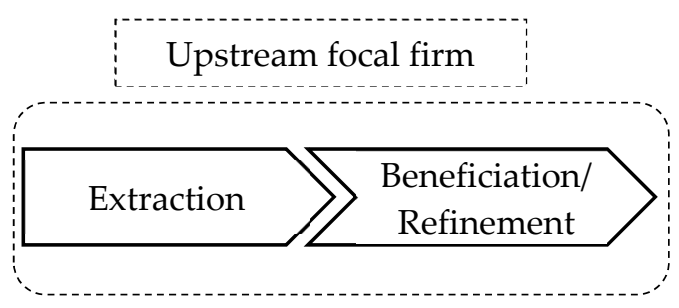

Upstream SC

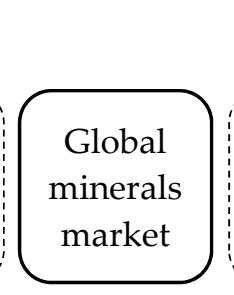

.

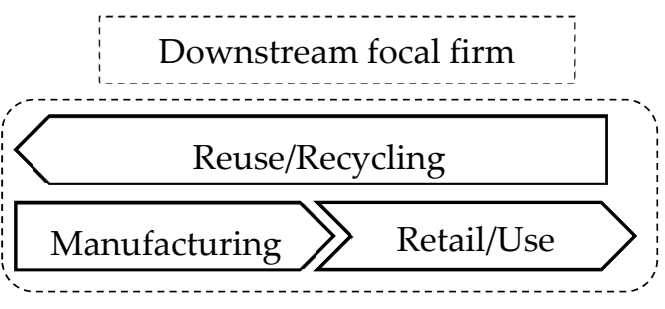

Downstream SC

Figure 1. Mineral SC concept [13] (p. 237).

\subsection{Introduction to Fairphone}

Fairphone started in 2010 as a campaign of the Waag Society in Amsterdam, mainly focused on creating awareness of conflict minerals within the smartphone industry. Since the demands of the campaign were not adequately taken up by the industry, the social enterprise, Fairphone, emerged in 2013 as the outcome of a crowd-funding campaign. With no prototype and limited working capital, the first 25,000 smartphones were pre-sold and, as at October 2015, the company had sold 75,000 phones with a revenue of $€ 27.4$ million [52]. The vision of the social enterprise is to design and produce a truly 'fair' phone with the help of its community. "To create positive social and environmental impact from the beginning to the end of a phone's life cycle" [15], Fairphone focuses on four main areas: long-lasting design, fair materials, good working conditions as well as reuse and recycling $[15,53]$. The Fairphone 2, an updated version, has been available since December 2015. Up until now, Fairphone has sold over 100,000 phones in total, with a community of 250,000 members on social media and their forum combined, and more than 50 employees [54].

The reasons that make Fairphone suitable for this case study are two-fold. First, the present research is based in the field of sustainability, where Fairphone can be considered as a pioneer within the smartphone industry [11]. The high number of sustainability awards, for example, the European Business Awards for the Environment 2016, confirm its pioneer status. Moreover, in October 2016, Fairphone 2 was the first smartphone to bear the sustainability certification Blue Angel, awarded by the German Federal Ministry for the Environment [54]. As Fairphone also targets the entire SC, the enterprise is a showcase project for SSCM in the electronic industry.

Second, Fairphone holds transparency and dialogues with stakeholders as principle guidelines for their business. By doing so, Fairphone not only communicates achievements but also openly discusses challenges and problems throughout the SC with its community [53]. Due to the willingness and openness of Fairphone to continuously discuss problems in their SC and the acknowledgment that "phones hold a complex story of the hundreds of people who helped make it" [15], Fairphone seems to embrace tensions, rather than avoiding or resisting them. Thus, Fairphone was chosen as the case firm for this research, focusing on paradox sustainability tensions. 


\subsection{Data Analysis}

For the case study of Fairphone, three method steps were conducted. First, a definition of paradox sustainability tensions was derived from the literature. Second, corresponding material was selected and its content analyzed, in accordance with Mayring [55]. Simultaneously, the relating practices, which were mentioned within the considered text passages, were collected. In a third step, Fairphone validated the findings of the content analysis. From the qualitative content analysis, seven paradox sustainability tensions along the SC of Fairphone were identified. Six of the paradox sustainability tensions were confirmed by the case company during the validation process. The definition of paradox sustainability tensions-derived deductively from the literature in Section 2, in the following in cursive-was slightly adjusted for this case study. Within the following qualitative content analysis, identified paradox sustainability tensions had to fulfill all of the following criteria:

1. Actors embrace the tensions between goals, rather than resisting or avoiding tensions.

In effect, actors identify and acknowledge paradoxes, instead of avoiding or simply accepting a trade-off between two competing goals.

2. Actors attend to competing and interrelated demands simultaneously.

Thus, actors actively seek strategies on how both demands can be addressed.

3. Paradoxes are dynamic demands which can be managed only by continuous cyclical responses in the form of practices.

Cyclical responses mean that tensions cannot be solved by the case firm within its sphere of influence and are restricted by its limited power and resources. However, a better state can be reached, and it is possible that new paradox tensions can emerge by solving one paradoxical tension.

4. Paradoxes are strongly linked to supply chain and sustainability issues.

This criterion was added since the case study focuses on paradox tensions within the fields of SCM and sustainability.

These criteria build the basis for the following qualitative content analysis, as proposed by Mayring [55]. This approach offers a rule-governed and inter-subjectively replicable process of categorizing text material. It is thus suitable for conducting exploratory case studies with interviews or other available texts and is extensively used in SSCM research [13,19,48].

According to Mayring [55], the first step of such an analysis is to define which material is included and to begin the material collection. The overall material which was used for the content analysis in this case study was primarily based on Fairphone's extensive direct communication. This public communication of sustainability issues is a major part of the case company's strategy and its approach to handle competing sustainability objectives. Analyzing this material is therefore a good way to dive deeper into the sustainability tensions of Fairphone. Thus, the first sources included the website of Fairphone as well as their blog where employees of Fairphone or managers of their key suppliers share information and experiences. Additionally, two research papers of NGOs were included. The first one is a survey on "How sustainable is the Fairphone 2?" published by the Fraunhofer IZM and the Deutsche Umwelthilfe [11]. In the survey, 48 experts from different organizations from Germany and Austria, e.g., Wuppertal Institut or Umweltbundesamt, evaluated Fairphone's approach and achievements. Subsequently, Fairphone commented on the findings and formulated responses to the survey. For the case study, primarily the responses of Fairphone were taken into account. The second research paper was a background paper about Fairphone, published by Germanwatch [12]. To put it into a nutshell, this case study includes material from Fairphone's direct communication on their website and blog as well as in form of their responses to the critique of experts within the survey. Additionally, external material—the Germanwatch background paper [12] and the expert survey itself [11]—was considered. 
The second step of qualitative content analysis—the descriptive analysis of the material—was omitted due to the small number of included material. The category selection, as the third step, was a means of defining categories to allow a qualitative analysis of the material and its content [55]. To do so, the derived paradox definition mentioned above served as a theoretical-deductive root category and coding guide. Following this coding guide, different paradox tensions were identified within the collected material as well as the SSCM practices applied to address them. This delivered the empirical insights called for by Van der Byl and Slawinski [25].

Subsequently, the results of the document analysis were written up and validated by a manager from the Resource Efficiency Department of Fairphone. Such a "communicative validation" [55] (p. 120) step ensures the correct interpretation of the data, i.e., their validity. In our case, the communicative validation process furthermore provided an update, as it contained several comments towards current developments related to the tensions. In total, six of the seven tensions were validated and altered in the validation process, while one tension had to be deleted. The validity of the results was further ensured by relating it to the theoretical characteristics identified in Section 2 [55]. The reliability of the results was ensured by a discursive coding of the tensions, including all authors. The coding was guided by the just-mentioned theoretical characteristics in Section 2, and its results are displayed and explained in the findings, as well as in Appendix A.

The six validated paradox tensions are outlined in Section 4 . The description of the identified paradox tensions and the corresponding practices, which were named within the considered text passages, is elaborated directly after the characterization of the tension.

\section{Findings of the Case Study}

\subsection{Identified Paradox Sustainability Tensions and Practices}

The following sub-section will elaborate on the paradox sustainability tensions and categorize it using the framework of Smith and Lewis [16]. The paradox sustainability tensions were identified using a traditional SSCM perspective. Nevertheless, the validation showed that Fairphone, as a social enterprise, does not fully adopt this perspective. Therefore, it does not perceive all these risks as tension, but more as a chance for creating social and environmental value.

Subsequently, the analyzed SSCM practices (written in brackets and cursive letters) are assigned to the SSCM practices from the Beske and Seuring [18] framework. Table A1 summarizes all tensions with the related SSCM practices and their localization in the SC in a table.

\subsubsection{Responsible Raw Material Extraction vs. Creation of Economic Prosperity}

Tension: At the upstream SC, the first identified paradox sustainability tension is within the goals of Fairphone: On the one hand, the company tries to comply with the demands of their customers by sourcing only responsible raw materials. On the other hand, Fairphone defines itself as a social enterprise and therefore strives to simultaneously create economic prosperity in conflict regions with some of the poorest people in the world. For that, raw materials have to be extracted in those very regions [11] (p. 9). However, in conflict regions, like the African Great Lakes Region, the extraction of raw material is closely linked to several human right violations, such as the expulsion of the local population, sexual violence, child labor, missing measures for the protection of health and work safety as well as environmental degradation. Moreover, the raw material extraction often serves as the main source for the financing of armed conflicts in those regions, and many of the related buyers try to avoid any raw materials from these regions ([12] (p. 2) [51,56]). The paradox tension inherent in this situation is created by the competing goals of meeting both goals: sourcing fair raw material while simultaneously creating economic prosperity for stakeholders in conflict affected regions. Fairphone embraces this tension by being aware of possible supply risks, but nevertheless sources some of its raw material in a socially responsible manner from conflict regions. This was also confirmed during the validation process, in which the company pointed out that it perceives 
the tension rather as an opportunity to increase the social benefit of their product than as a risk. Fairphone's initiative establishes a stable demand for responsibly produced minerals, which, in turn, reduces the demand uncertainty at the supplier side and stabilizes the income of suppliers [20,21]. Thus, the company contributes to better conditions in these regions. Nevertheless, the tension cannot be solved by the case firm within its sphere of influence that is restricted by its limited power and with that remains a paradox. Performing paradoxes can appear when organizations must decide between competing strategies and goals to meet contradictory demands of multiple-internal and external—stakeholders simultaneously [16]. Thus, according to Smith and Lewis [16], this tension illustrates a performing paradox.

Practices: Two different approaches by Fairphone can be identified to address this paradox sustainability tension at the extraction stage. The first approach is directly related to Fairphone's decision to source critical raw materials in crisis and conflict regions, in order to improve the conditions for the poorest people who will benefit the most from it. To meet both interrelated demands, Fairphone works closely with carefully selected suppliers (Continuity: SC Partner Selection) and actively tries to improve the working conditions in the mining areas. Practices include, for instance, site visits and assessments [57,58] (Risk Management: Selective Monitoring). In doing so, Fairphone collaborates with local NGOs and supports existing initiatives (Pro-Activity: Stakeholder Management; Risk Management: Pressure Groups), as also suggested by Pagell and Wu [59], to achieve a more sustainable SC. Up until now, the efforts focused only on conflict-free tin, tantalum, tungsten and gold, but will be extended to other raw materials in the future [11] (pp. 9-10). The most recent development is a project to set up a more responsible cobalt mining process [60].

In a second approach, Fairphone tries to simultaneously reduce the amount of virgin raw materials by substituting critical materials with recycling sources by developing new processes [11] (p. 10) (Pro-Activity: Innovation) (see also [2,13]). Following this second approach, the demand for recycling materials consequently increases and hence, a new paradoxical tension arises, which is described next.

\subsubsection{Increasing Use and Availability of Recycling Materials vs. Efficient Sourcing of Raw Materials}

Tension: To enhance the environmental friendliness of their products, Fairphone aims to increase the use and availability of recycling materials. With design for disassembly approaches through the modular construction of the smartphone, Fairphone has already created the preconditions for increased recycling of their products [61]. The company pointed out that recycled material is often cheaper and easier to get than raw material, e.g., gold. However, many of the current take-back and recycling programs are not accepted or used by customers. Thus, current recycling programs cannot meet Fairphone's desired recycling rates. Moreover, building new and stable recycling structures dedicated to their own products would be highly expensive (see also [62]). The unstable recycling volumes represent a supply uncertainty for Fairphone. The company needs to ensure a certain minimum of cost efficiency in the sourcing process of raw materials to remain competitive. As a result, they cannot directly increase the use of recycling materials as strongly as they would like and their product can technically allow [11] (p. 21). Instead, Fairphone actively drives the recycling processes in the industry in general, to increase the availability of recycling material in the industry's supply system. This dilemma can be categorized as a paradox tension between Learning and Organizing. Fairphone seeks stable and efficient sourcing structures and simultaneously tries to stay flexible in their routines to be open to new and innovative sources, e.g., the availability of recycling materials.

Practices: To address this paradox sustainability tension, Fairphone constantly searches for opportunities to efficiently recycle more materials (Pro-Activity: Innovation). During the validation, the case company emphasized that they consider it to be their responsibility as a manufacturer to take out unused electronics from the market as much as possible for reuse or recycling purposes. In contrast to most other providers, Fairphone's recycling program, which is already required by European law [62], is actively promoted, in order to make it as easy as possible for the customers to send their old smartphone (no matter which brand) back to Fairphone [63]. Moreover, Fairphone supports programs and initiatives 
(Pro-Activity: Stakeholder Management) to collect electrical scrap from mobile phones in Ghana, which is currently extended to Ruanda, Cameroon and Uganda ([11] (p. 21), [12] (p. 4)). These practices contribute to the company's aim of reducing the environmental, as well as social, impacts of their products, since virgin material can be substituted.

\subsubsection{Socially Responsible Production Conditions vs. Competitive Production Site}

Tension: Coming to the downstream SC, the first stage is the manufacturing process. Fairphone faces a paradox since the company wants to ensure socially responsible working conditions, but produces in China. The country leads in manufacturing know-how on electronic devices; however, China is also known for its low social standards and violations against basic working conditions [11] (p. 11), [64]. In effect, a competitive production site with the high social responsible production conditions, such as those demanded by Fairphone, does not exist within the current smartphone economy. The two demands therefore compete and result in a paradox organizational tension, since Fairphone still tries to meet both demands simultaneously. Like tension (1), this situation represents an instance in which Fairphone faces supply uncertainty in terms of production conditions which initially do not fit the company's requirements and thus need to be adjusted [20]. However, in turn, the continuous involvement of Fairphone and their demand helps to reduce the demand uncertainty for responsibly operating suppliers. With that, Fairphone's actions in China contribute to better working conditions, but only for their own short production time in the factories. For a continuing impact, more power and resources would be necessary-an aspect which is another criterion of a paradox tension. This paradoxical tension between Organizing and Performing can be described as tension between specific processes and certain outcomes [16].

Practices: The approach to address this paradox sustainability tension is directly related to Fairphone's decision to manufacture in China, where improvements in working conditions will show the biggest effects [11] (p. 11). Therefore, Fairphone is highly engaged in the search for its first-tier supplier (Continuity: SC Partner Selection), which can be seen as a core challenge in the electronic SC regarding sustainability [47], and now collaborates closely with the manufacturing site to improve working conditions. One project manager of Fairphone is directly living on site [12] (p. 3) and a worker welfare fund was founded. Moreover, training programs were established (Continuity: SC Partner Development). The goal of both practices is to improve the employee representation and the implementation of communication between workers and management. Additionally, a systematic documentation and analysis of social and economic performance to detect possible connections is in progress [11] (p. 12) (Collaboration: Enhanced Communication).

\subsubsection{No Work Overtime in Production vs. Delivery Capability}

Tension: A more specified organizational tension in the manufacturing process is related to work over time. As a retailer, Fairphone has to ensure compliance with the delivery deadline, to meet the needs of their customers. Consequently, to make up for delays, e.g., caused by problems with incoming materials from other suppliers, overtime is a common practice and often considered unavoidable [13,44]. However, as part of their strategy to guarantee socially responsible working conditions, one of Fairphone's goals is to eliminate work overtime. Subsequently, a paradox sustainability tension arises between the interrelated demands of the avoidance of work overtime and the assurance of delivery capability surfaces. The validation showed that the company embraces this tension by attending to both goals simultaneously, e.g., by planning the production schedule together with the assembler, instead of simply setting production deadlines. While some of the customers are willing to wait for a product produced without work overtime - at least up to a certain point—others might not tolerate any delays at all. The tension in this case is a performing paradox because Fairphone tries to meet two contradictory and competing goals.

Practices: The practices of Fairphone to address this tension within the manufacturing process are largely based on the close collaboration and long-term relationship with its first-tier supplier in China, which has already been mentioned in tension (3), to build up trust (Continuity: Long-Term Relationships). In general, Fairphone tries to avoid short-term product life cycles and peak times, to prevent overtime 
hours in production [12] (p. 4). When facing production delays, Fairphone is not afraid to postpone the delivery date for customers instead of insisting on it. Through this measure, they do not have to ask for speedier production which would require temporary agency employees or overtime hours. This is of course only possible as Fairphone's customers, in general, accept such delays, to help to achieve the goals for better working conditions (Pro-Activity: Stakeholder Management). Nevertheless, timely communication from both sides-the manufacturer and customers (Collaboration: Enhanced communication) -in the case of production issues are the prerequisite for measures like this [65].

\subsubsection{Demand for Transparency vs. Functioning Supply Chain}

Tension: This identified paradox sustainability tension relates to the SC in its entirety. The very high transparency demands, which are a basic principle of Fairphone, can mostly not be fulfilled, due to the enormous complexity of the SC of smartphones. For illustration, the display module by itself encompasses 50 different substances [11] (p. 19). Additionally, Fairphone sometimes has no direct access to even basic information, such as the origin of materials or working conditions, and their suppliers are not bound to provide them [11] (p. 22). Therefore, in the current structure of the smartphone economy, the high demand for transparency must be seen as competing with the demand for a functioning SC. However, Fairphone embraces this tension, rather than accepting the trade-off, by actively communicating the emerging problems of transparency and seeking for strategies to address both demands simultaneously. Thus, it illustrates a paradox tension between Organizing and Performing, e.g., between a process and its outcome.

Practices: The practices of Fairphone to address this paradox sustainability tension include publishing a detailed cost-breakdown of the smartphone [66] as well as a so-called source map, which provides basic information about all involved suppliers [67]. It is aiming to inform and involve the customers (Pro-Activity: Stakeholder Management). Since customers are part of the SC context, these practices can also be classified as Enhanced Communication, as a part of the category of Collaboration. Instead of focusing on only some particular projects in this field, Fairphone is using transparency as a general guideline for their management and communication [11] (p. 22).

\subsubsection{Environmental Friendly Production vs. Maintaining of Production}

Tension: Like paradox sustainability tension (5), this identified organizational tension relates to the SC in its entirety. As shown before, smartphones encompass a high number of potential pollutants. Due to the lack of environmental friendly substitutes, the production of a smartphone is not (yet) completely feasible without potential pollutants [11] (p. 15), [58]. Fairphone stated that even though all the actors of the SC need to conform with EU law on chemicals if they are to sell that product in Europe, the visibility of the numerous substances (e.g., PVC) not falling under legislation is very limited. The paradox results from the simple fact that Fairphone cannot produce their smartphone in an entirely environmental friendly way, as is their ambition, but still want to maintain their production, as is the nature of their business. During the validation, the case company emphasized that it never claimed or communicated to produce an entirely environmental friendly smartphone, but that they strive for it. However, current processes do not comply with this goal. Again, instead of just accepting this trade-off, Fairphone embraces the tension between the goals and seeks for strategies for how both demands can be addressed, even though the tension cannot be solved by the case firm within its sphere of influence. This creates another paradox between Organizing and Performing.

Practices: This paradox sustainability tension is addressed by Fairphone with increased research activities (Pro-Activity: Innovation, LCA). In a first step, Fairphone aims to increase the transparency of the production process with the used potential pollutants, which has been already detected to be a critical issue within the paradox tension (5). A comment from the case company was that they try to collect the full material declarations, even though it is challenging, because the actors in the SC share the proof of their compliance with legislations (e.g., REACH and ROHS), but are less open about 
information that goes beyond this. Research projects should help to discover which measures promise the biggest effect in this field [11] (p. 19).

\subsection{Synthesis of the Identified Paradox Sustainability Tensions and Practices}

Table 1 summarizes the six identified SSCM practices according to Beske and Seuring [18] in a cross-tabulation against the organization tensions as defined by Smith and Lewis [16] as well as the TBL dimensions. This enables a closer look into three relationships which arise from Fairphone's management of the tensions. The case specific relationship of (a) TBL tensions and organizational tensions; (b) organizational tensions and SSCM practices; and (c) TBL tensions and SSCM practices. We will discuss the results of these relationships against the current literature on sustainability in the electronics SC in the following section to answer the RQs and derive the main contributions.

Table 1. Cross-tabulation of organizational and triple bottom line (TBL) tensions and the applied sustainable supply chain management (SSCM) practices.

\begin{tabular}{|c|c|c|c|c|c|}
\hline & & \multicolumn{4}{|c|}{ Organizational Tensions [16] } \\
\hline & & Performing & Performing:Organizing & Learning:Organizing & $\begin{array}{c}\text { No. of } \\
\text { Tensions }\end{array}$ \\
\hline \multirow{2}{*}{$\begin{array}{c}\text { TBL } \\
\text { tensions }\end{array}$} & $\begin{array}{l}\text { Environmental- } \\
\text { Economic }\end{array}$ & - & $\begin{array}{c}\text { Tension (6) } \\
2 \times \text { Pro-Activity }\end{array}$ & $\begin{array}{c}\text { Tension }(2) \\
3 \times \text { Pro-Activity }\end{array}$ & (2) and (6) \\
\hline & $\begin{array}{l}\text { Social- } \\
\text { Economic }\end{array}$ & $\begin{array}{c}\text { Tensions }(1) \text { and }(4) \\
1 \times \text { Collaboration } \\
2 \times \text { Continuity } \\
3 \times \text { Pro-Activity } \\
3 \times \text { Risk Management }\end{array}$ & $\begin{array}{c}\text { Tensions }(3) \text { and }(5) \\
1 \times \text { Collaboration } \\
3 \times \text { Continuity } \\
4 \times \text { Pro-Activity }\end{array}$ & - & $\begin{array}{l}(1),(3),(4) \\
\text { and (5) }\end{array}$ \\
\hline
\end{tabular}

\section{Discussion}

\subsection{Paradox Sustainability Tensions in Electronic Supply Chains}

Looking at the number of TBL tensions, the prevalence of social issues becomes evident in Fairphone's SC. Four of the six tensions address social issues, while only two draw on environmental issues. This prevalence of social issues is typical in the context of minerals and electronic products [10-13]. However, it offers to add to the general discussion on SSCM, which is, to date, lagging behind in the social dimension of sustainability $[19,31]$.

Regarding the organizational tensions, all identified paradox tensions, except tension (2), occurred within or between the Performing and Organizing paradox categories. The Performing dimension represents the strategic goals of Fairphone, which includes the assurance of socially responsible production conditions and the transparency of the SC. By doing so, Fairphone responds to the stakeholder pressure and customer demand for more sustainable products. These pressures and demands are seen as a major trigger for SSCM $[19,26,30]$, which is supported by the presented case.

Paradoxes of the Organizing dimension are associated with current structures and processes of the smartphone industry. To a substantial extent, Fairphone is bound to the conventions of the industry to guarantee a functioning SC and a competitive production site. This is fully in line with current SSCM research which sees a "supply chain that performs well on traditional operational metrics is a foundation of a sustainable supply chain" [59] (p. 52). Thus, economic survival must be ensured, in order to meet the conflicting goals as well. Still, Fairphone opens up a new way of addressing economic success in SSCM, which, in general, holds "that competitiveness would be maintained through meeting customer needs and related economic criteria" [19] (p. 1700). In contrast to their competitors, Fairphone meets their customer requirements by openly communicating sustainability achievements as well as shortcomings and how they deal with them, i.e., the sustainability tensions in their market. This contrasts with the focus of mainstream companies on reporting only, which often lacks action orientation [68]. 
One could argue that the three paradox tensions surfacing between Performing and Organizing, represent a kind of meta-tension for Fairphone. This could be also interpreted as due to the fact that it is the only organizational tension spanning both environmental and social dimension. The current structures and production situation in the smartphone sector simply do not allow Fairphone to fully comply with many of their own goals and stakeholder demands. For example, hazardous chemicals cannot be substituted in current production processes [69] and a partially non-transparency must be accepted due to the high complexity of the SC network [33] needed to produce smartphones. However, addressing these tensions is a powerful path towards resolving the current shortcomings in sustainability and creating a stronger customer interest in the topic. In this regard, Fairphone is taking a leading role in incorporating non-traditional members into its SC, as called for by Pagell and Wu [59]. The pro-active stakeholder involvement and management of the company, by enforcing workers and unions in China, represents a strong case for a SC "re-conceptualization" [59]. This approach mobilizes, for example, the innovation capabilities of the stakeholders who interact with Fairphone and thus, offers the potential to differentiate from the competitors [32,59].

In contrast to these dimensions, paradox tensions of the Learning category were only identified once and the dimension of Belonging is even completely missing in the results. The reasons for this could be various. Since paradox tensions of the Belonging kind surface between individuals and the organization, more inside knowledge of the company could help to identify these paradoxes. This represents one of the limitations of the study. However, further research could capture the dynamics inside the company, which would be necessary to analyze Belonging paradox tensions. For doing so, we suggest using research methods like, e.g., interviews, which are more suitable at an individual level.

In general, we see the prevalence of social sustainability arguments directed at the strategic goals of Fairphone, i.e., the Performing tensions. These tensions represent the core of Fairphone's value proposition and are at the heart of their operations. The validation of the tensions revealed that Fairphone's approach in seeing the creation of social and environmental value as one of their goals contrasts with the classic definition of supply and demand risks [20,21]. For instance, Fairphone perceives the sourcing of materials, which are at risk of being associated with conflict affected regions, more as a chance to create social value. This changes the currently dominating notion of having conflict minerals in one's SC as a reputational risk $[13,50,51,55,56]$ into a potential value proposition, which might create a competitive advantage due to enhanced customer value $[19,21]$.

\subsection{SSCM Practices to Address Paradox Sustainability Tensions in Electronic Supply Chains}

On the managerial side, a variety of practices are chosen by Fairphone to address the paradox sustainability tension. Looking at the SSCM practices addressed in RQ2, the category of Orientation towards the TBL and SCM is not mentioned. This is not surprising since sustainability and SC practices are strongly rooted in the organizational culture of Fairphone.

As shown in Table 1, there is a prevalence of processual practices on Risk Management and especially, Pro-Activity. Practices of the Pro-Activity category are by far the most identified, contrasting with the findings by Sauer and Seuring [13] on the minerals sector in general. This underlines the pro-active approach of Fairphone and its suitability as a unique and revelatory case [24], which provides industry evidence for the adoption of the paradox approach.

Contrastingly, structural practices that stem from the categories Continuity and Collaboration have only been identified seven times and solely in the social tension. Those practices address both the performing side, with its goals and strategies, as well as the organizing dimension, with its processes. By doing so, the SC can be adjusted to the customer needs, which are collected in the stakeholder community. This implementation is thoroughly documented to the community to signal the desired change and to satisfy the customer push for sustainability improvements. This continuous improvement, even on a small scale, provides Fairphone's customer value and enables the acquisition of the required capital for the upgrading of SC sustainability. Interestingly, these structural practices are 
applied to manage Performing and the Performing:Organizing tensions at the intersection of goals and structures, but not for the Learning:Organizing tension at the verge of change and structure. In effect, Fairphone employs the structural practices in their direct sourcing activities with mines and assembly facilities in order to resolve social issues which are at the heart of their social vision. Furthermore, they are easier to change as they include the investment in human factors instead of changes of capital intensive equipment.

Contrary to these structural practices, Fairphone only uses practices that stem from the processual category of Pro-Activity to address the environmental tensions. They relate to the SC in its entirety, and the Performing:Organizing and Learning:Organizing tensions are among strategic goals as well as change and structures. By using these practices, Fairphone addresses only the Performing and Learning dimension of the paradoxes, i.e., their strategic goals and changes. Measures like the Source Map or LCA do not address the Organizing level, i.e., the structure and processes. They address the demand for transparency or environmentally friendly product design. However, transparency is an essential pre-requisite of in depth collaboration for sustainability in the SC $[13,18]$. These actions towards a fully transparent SC are again beyond the industry norm. These transparency actions may lay open sustainability challenges, which cannot immediately be resolved, i.e., further paradox tensions $[16,17]$. Still, the customers appreciate the efforts towards open communication, but will most likely request further improvements in the future.

Another effect beyond Fairphone and its SC is the rising customer and stakeholder awareness which Fairphone brings into the electronic industry and its SC in general. This will likely put pressure on the other players in the electronic SC to engage in similar actions [11,12]. However, Fairphone's market share is still small, and bigger players will potentially face higher pressure as their potential impact is bigger.

Thus, there are two main managerial takeaways. First, sustainability pioneers in the electronic SC excel in stakeholder communication. This, in turn, leads to the second takeaway: that managers in the electronic SC have to be aware of these developments and prepare for SSCM actions in their SC, too.

In total, it is remarkable that the practices used by Fairphone to address the paradox tensions in their SC are primarily of a processual nature and only secondarily of a structural nature. This again emphasizes Fairphone's lacking power to change structures in the market. The more influential way of enhancing sustainability for the company is changing processes in existing structures. Still, such actions deliver a possible starting point for changed routines and eventually changing structures. This line of argumentation points towards the investigations on a company level which allows deeper insights into structure and processes. Future research could take up this route and apply, for example, institutional theory considerations, which have already touched upon the so-called "coupling" of structures and processes.

\subsection{Policy Implications}

The case of Fairphone is also interesting for policy makers, who can support pioneers in changing regional industries towards more sustainable practices [42]. In particular, Fairphone's aspiration for tackling the sustainability challenges in existing SC in the global South is promising in this regard. This upgrading of existing mines and facilities by means of worker welfare funds, training and the cooperation with NGOs offers a path for raw material exporting nations to enhance the development impact of their raw material sectors. Of course, these private actions rely on credibility and transparency, which are also dependent on state actions against corruption and towards sustainable development [13,52]. Furthermore, governmental policies, such as relevant regulations or standards for green materials and manufacturing processes, public-funded incentives for supply chain collaborations or consistent promotions of consumers' awareness for sustainability, can encourage the industrial development [45]. If the states fail to enable responsible business practices, private actors will blame them for shortcomings in sustainability. The companies can then still avoid the resolution of tensions 
due to missing policy actions. In effect, policy makers represent critical enablers for addressing and resolving sustainability tensions [42].

Another policy-related issue is the concentration of mines and manufacturing facilities in single countries, such as China [56,69]. This concentration provides China with a lot of power in the electronic $\mathrm{SC}$, which is based on the almost perfect supply monopoly but also the concentration of manufacturing know-how in the country [64]. These factors enable a policy driven enhancement of sustainability as the market pressure is weaker as in more globalized industries. Such a policy towards better working conditions and less environmental pollution could impact the entire electronic industry [42], as all electronic SCs cross China at some point.

\section{Conclusions}

The purpose of our research was two-fold. First, we wanted to examine which kind of paradox sustainability tensions can be identified in electronic SCs. Second, we wanted to identify the practices that are used to address them. To do so, a case study of Fairphone, in the form of a qualitative content analysis, was conducted and validated by the company. Subsequently, the case study results were connected to the theory to ensure its validity [55]. The paradox tensions were categorized based on the framework of Smith and Lewis [16], and the practices based on the SSCM framework of Seuring and Beske [18].

The identification and categorization process of the paradox tensions was conducted in a rule governed process by the authors together and has been documented to ensure reliability [55]. However, we acknowledge that a distinct theoretical categorization of the case study results is not always possible and a categorization by others might differ from ours. All identified paradox tensions within the case study were covered by the framework of Smith and Lewis [16]. The same holds true for the identified practices which were categorized according to the SSCM framework of Seuring and Beske [18].

In the case study, paradox tensions within and between the Performing and the Organizing dimensions were identified most frequently. The most identified practices used to address paradoxical tensions fell under the Pro-Activity category. Surprisingly, practices of the Collaboration and Continuity categories were not as frequently used as expected. Although some specific patterns could be observed (see Section 5), general statements cannot be derived from the present study, as it is a single case, aimed at revealing novel and unique insights [24]. Furthermore, the case firm represents a special case, since Fairphone is a social enterprise, and thus, goals and practices differ from that of the dominant, conventional companies of the smartphone and electronic industry. However, conventional enterprises probably face similar challenges and organizational tensions when it comes to sustainability issues. Given this, further research could focus on how other (conventional) companies in the electronic industry deal with these sustainability tensions, and if they are also adopting a paradox approach or simply stay within a win-win or trade-off approach. In the case that similar tensions are identified, the practices of Fairphone could be compared with those of other enterprises to see if specific patterns in choosing practices to address the sustainability tensions can be observed. Furthermore, future research could deepen the understanding of the benefits of addressing and resolving tensions by moving into quantitative approaches. These could build on simulation approaches, to enable predictions on the potential impact of pioneers and niche products in well-established SCs like the electronic SC.

While most of the SSCM research focuses on win-win and-to a certain degree-on trade-off situations $[26,28,30]$, paradoxes within the field have been mostly ignored. However, it is easy to imagine that companies engaging in SCM are regularly confronted with paradoxical tensions, whether consciously or not. The paradox theory in combination with SSCM is a highly interesting research field. Due to its complexity and relevance for sustainability, we believe that the electronics industry is a suitable sector to explore this unique research field. We hope that our paper serves as a starting point for further research and we look forward to any contribution within the SSCM field.

Acknowledgments: We would like to sincerely thank the anonymous reviewers and Stephan Vachon for their constructive feedback that helped us to improve the manuscript significantly. The open access publication costs were covered by the "Open-Access-Publikationsfonds" of the University of Kassel, which is financed by the 
German Research Foundation (DFG) and the Library of the University of Kassel. The third author is financially supported by the German Federal Ministry of Education and Research (BMBF) (grant No. 01UT140).

Author Contributions: All authors designed the study together. Anne-Kristin Geisbüsch, Patrick Schöpflin, and Axel Zehendner conducted the coding and interpretation of the material and contributed to the writing of all sections of the paper. Carolin Brix-Asala and Philipp Christopher Sauer also contributed to the writing of all sections and were the main contributors to the revision of the paper.

Conflicts of Interest: The authors declare no conflict of interest.

\section{Appendix A}

Table A1. Summary of the categorizations from identified paradox sustainability tensions and practices.

\begin{tabular}{|c|c|c|}
\hline $\begin{array}{l}\text { Organizational } \\
\text { Tensions [16] }\end{array}$ & $\begin{array}{l}\text { Paradox Sustainability Tension and } \\
\text { Its Localization in the SC [13] }\end{array}$ & $\begin{array}{l}\text { Inductively Identified Practices and Related } \\
\text { Categorization into Deductive SSCM Practices [18] }\end{array}$ \\
\hline \multirow[t]{2}{*}{ Performing } & $\begin{array}{l}\text { (1) Responsible raw material extraction } \\
\text { vs. Creation of economic prosperity in } \\
\text { the extraction stage }\end{array}$ & $\begin{array}{l}\text { Supplier Selection } \\
\text { - Continuity: SC partner selection } \\
\text { Site visits and informal assessments } \\
\text { - Risk-Management: selective monitoring } \\
\text { Certifications } \\
\text { - Risk Management: standards and certification } \\
\text { Collaboration with NGOs } \\
\text { - Pro-Activity: stakeholder management } \\
\text { - Risk Management: pressure groups } \\
\text { Substitute critical materials with recycling sources } \\
\text { - Pro-Activity: innovation }\end{array}$ \\
\hline & $\begin{array}{l}\text { (4) No work overtime in production vs. } \\
\text { Delivery capability in the } \\
\text { manufacturing stage }\end{array}$ & $\begin{array}{l}\text { Long-term relationships } \\
\text { - Continuity: long-term relationships } \\
\text { Timely communication } \\
\text { - Collaboration: enhanced communication } \\
\text { - Pro-Activity: stakeholder management }\end{array}$ \\
\hline \multirow[t]{3}{*}{ Performing:organizing } & $\begin{array}{l}\text { (3) Socially responsible production } \\
\text { conditions vs. Competitive production } \\
\text { site in the manufacturing stage }\end{array}$ & $\begin{array}{l}\text { Supplier Selection } \\
\text { - Continuity: SC partner selection } \\
\text { Worker welfare fund } \\
\text { • Continuity: SC partner development } \\
\text { Training programs } \\
\text { - Continuity: SC partner development } \\
\text { Systematic documentation } \\
\text { - Collaboration: enhanced communication }\end{array}$ \\
\hline & $\begin{array}{l}\text { (5) Demand for transparency vs. } \\
\text { Functioning SC in the entire SC }\end{array}$ & $\begin{array}{l}\text { Cost break-down } \\
\text { - Pro-Activity: Stakeholder Management } \\
\text { Source Map } \\
\text { - Pro-Activity: Stakeholder Management }\end{array}$ \\
\hline & $\begin{array}{l}\text { (6) Environmental friendly production } \\
\text { vs. Maintaining of production in the } \\
\text { entire SC }\end{array}$ & $\begin{array}{l}\text { Research } \\
\text { - Pro-Activity: innovation } \\
\text { LCA } \\
\text { - Pro-Activity: LCA }\end{array}$ \\
\hline Learning:Organizing & $\begin{array}{l}\text { (2) Increasing use and availability of } \\
\text { recycling materials vs. Efficient sourcing } \\
\text { of raw materials in the extraction stage }\end{array}$ & $\begin{array}{l}\text { Searching for opportunities } \\
\text { - Pro-Activity: innovation } \\
\text { Supporting Initiatives } \\
\text { - Pro-Activity: stakeholder management } \\
\text { Information of customers } \\
\text { - Pro-Activity: stakeholder management }\end{array}$ \\
\hline
\end{tabular}

\section{References}

1. Boren, Z. There Are Officially More Mobile Devices That People in the World. Available online: http:/ / www.independent.co.uk/life-style/gadgets-and-tech/news / there-are-officially-more-mobiledevices-than-people-in-the-world-9780518.html (accessed on 29 December 2017).

2. Golev, A.; Scott, M.; Erskine, P.D.; Ali, S.H.; Ballantyne, G.R. Rare earths supply chains: Current status, constraints and opportunities. Resour. Policy 2014, 41, 52-59. [CrossRef]

3. Leong, K.; Ogunseitan, O.A. Risks of toxic ash from artisanal mining of discarded cellphones. J. Hazard. Mater. 2014, 278, 1-7. 
4. McLellan, B.C.; Corder, G.D.; Golev, A.; Ali, S.H. Sustainability of the Rare Earths Industry. Procedia Environ. Sci. 2014, 20, 280-287. [CrossRef]

5. Chan, J.; Pun, N.; Selden, M. The politics of global production: Apple, Foxconn and China's new working class. New Technol. Work Employ. 2013, 28, 100-115. [CrossRef]

6. Leong, A.; Padita, S. Made in China-Electronic Workers in the World's Fastest Growing Economy. In Challenging the Chip_Labor Rights and Environmental Justice in the Global Electronics Industry; Smith, T., Sonnenfeld, D.A., Pellow, D.N., Eds.; Temple University Press: Philadelphia, PA, USA, 2006; pp. 55-69. ISBN 159-2-13330-4.

7. Padita, S. Electronics Workers in India. In Challenging the Chip_Labor Rights and Environmental Justice in the Global Electronics Industry; Smith, T., Sonnenfeld, D.A., Pellow, D.N., Eds.; Temple University Press: Philadelphia, PA, USA, 2006; pp. 83-95. ISBN 159-2-13330-4.

8. Ninlawan, C.; Seksan, P.; Tossapol, K.; Pilada, W. The implementation of green supply chain management practices in electronics industry. In Proceedings of the International Multi Conference of Engineers and Computer Scientists, Hong Kong, China, 17-19 March 2010; pp. 17-19.

9. Gordon, R.B.; Bertram, M.; Graedel, T.E. Metal stocks and sustainability. Proc. Natl. Acad. Sci. USA 2006, 103, 1209-1214. [CrossRef] [PubMed]

10. Wernink, T.; Strahl, C. Fairphone: Sustainability from the Inside-Out and Outside-In. In Sustainable Value Chain Management; D’heur, M., Ed.; Springer: Cham, Switzerland, 2015; pp. 123-139. ISBN 978-3-319-12142-0.

11. Fraunhofer IZM; Deutsche Umwelthilfe. Wie Nachhaltig ist das Fairphone 2? Available online: http:// www.duh.de/uploads/media/160701_Fraunhofer_DUH_Nachhaltigkeit_des_Fairphone2_Endbericht.pdf (accessed on 29 December 2017).

12. Germanwatch. Im Germanwatch-Blickpunkt: Das Fairphone. Available online: https://germanwatch.org/ de/download/8883.pdf (accessed on 29 December 2017).

13. Sauer, P.C.; Seuring, S. Sustainable supply chain management for minerals. J. Clean. Prod. 2017, 151, $235-249$. [CrossRef]

14. London Metal Exchange. Trading on the LME. Available online: https://www.lme.com/en-GB/Trading (accessed on 20 December 2017).

15. Fairphone. Our Goals. Available online: https:/ /www.fairphone.com/en/our-goals/ (accessed on 29 December 2017).

16. Smith, W.K.; Lewis, M. Toward a theory of paradox: A dynamic equilibrium model of organizing. Acad. Manag. Rev. 2011, 36, 381-403.

17. Hahn, T.; Figge, F.; Pinkse, J.; Preuss, L. A Paradox Perspective on Corporate Sustainability: Descriptive, Instrumental, and Normative Aspects. J. Bus. Ethics 2017, 32, 1-14. [CrossRef]

18. Beske, P.; Seuring, S. Putting sustainability into supply chain management. Supply Chain Manag. Int. J. 2014, 19, 322-331. [CrossRef]

19. Seuring, S.; Müller, M. From a literature review to a conceptual framework for sustainable supply chain management. J. Clean. Prod. 2008, 16, 1699-1710. [CrossRef]

20. Chen, I.J.; Paulraj, A. Towards a theory of supply chain management: The constructs and measurements. J. Oper. Manag. 2004, 22, 119-150. [CrossRef]

21. Manuj, I.; Mentzer, J.T. Global supply chain risk management. J. Bus. Logist. 2008, 29, 133-155. [CrossRef]

22. Giurco, D.; Petrie, J.G. Strategies for reducing the carbon footprint of copper: New technologies, more recycling or demand management? Miner. Eng. 2007, 20, 842-853. [CrossRef]

23. Hofmann, H.; Schleper, M.C.; Blome, C. Conflict Minerals and Supply Chain Due Diligence: An Exploratory Study of Multi-tier Supply Chains. J. Bus. Ethics 2015. [CrossRef]

24. Yin, R.K. Case Study Research: Design and Methods, 3rd ed.; Sage: Thousand Oaks, CA, USA; London, UK; New Delhi, India, 2003; ISBN 076-1-92553-8.

25. Van der Byl, C.A.; Slawinski, N. Embracing Tensions in Corporate Sustainability: A Review of Research from Win-Wins and Trade-Offs to Paradoxes and Beyond. Organ. Environ. 2015, 28, 54-79. [CrossRef]

26. Brandenburg, M.; Rebs, T. Sustainable supply chain management: A modeling perspective. Ann. Oper. Res. 2015, 229, 213-252. [CrossRef]

27. Pagell, M.; Shevchenko, A. Why Research in Sustainable Supply Chain Management Should Have no Future. J. Supply Chain Manag. 2014, 50, 44-55. [CrossRef]

28. Seuring, S.; Müller, M. Core issues in sustainable supply chain management-A Delphi study. Bus. Strategy Environ. 2008, 17, 455-466. [CrossRef] 
29. Matthews, L.; Power, D.; Touboulic, A.; Marques, L. Building Bridges: Toward Alternative Theory of Sustainable Supply Chain Management. J. Supply Chain Manag. 2016, 52, 82-94. [CrossRef]

30. Rebs, T.; Brandenburg, M.; Seuring, S.; Stohler, M. Stakeholder influences and risks in sustainable supply chain management. Bus. Res. 2017. [CrossRef]

31. Yawar, S.A.; Seuring, S. Management of Social Issues in Supply Chains: A Literature Review. J. Bus. Ethics 2017, 141, 621-643. [CrossRef]

32. Hahn, T.; Pinkse, J.; Preuss, L.; Figge, F. Tensions in corporate sustainability: Towards an integrative framework. J. Bus. Ethics 2014, 127, 297-316. [CrossRef]

33. Surana, A.; Kumara, S.; Greaves, M.; Raghavan, U.N. Supply-chain networks: A complex adaptive systems perspective. Int. J. Prod. Res. 2005, 43, 4235-4265. [CrossRef]

34. Waller, M.A.; Fawcett, S.E.; Johnson, J.L. The Luxury Paradox: How Systems Thinking and Supply Chain Collaboration Can Bring Sustainability into Mainstream Practice. J. Bus. Logist. 2015, 36, 303-305. [CrossRef]

35. Jones, P.; Hillier, D.; Comfort, D. Sustainability in the hospitality industry. Int. J. Contemp. Hosp. Manag. 2016, 28, 36-67. [CrossRef]

36. Yuan, R.; Liu, M.J.; Chong, A.Y.-L.; Tan, K.H. An empirical analysis of consumer motivation towards reverse exchange. Supply Chain Manag. Int. J. 2016, 21, 180-193. [CrossRef]

37. Schmidt, C.G.; Foerstl, K.; Schaltenbrand, B. The Supply Chain Position Paradox: Green Practices and Firm Performance. J. Supply Chain Manag. 2017, 53, 3-25. [CrossRef]

38. Steinfeld, J.; McCue, C.; Prier, E. Professionalism as social responsibility in procurement and administration. Eur. Bus. Rev. 2017, 29, 320-343. [CrossRef]

39. Aragon-Correa, J.A.; Marcus, A.; Hurtado-Torres, N. The Natural Environmental Strategies of International Firms: Old Controversies and New Evidence on Performance and Disclosure. Acad. Manag. Perspect. 2016, 30, 24-39. [CrossRef]

40. Wong, J.Y.; Dhanesh, G.S. Communicating Corporate Social Responsibility (CSR) in the Luxury Industry. Manag. Commun. Q. 2016, 31, 88-112. [CrossRef]

41. Collins, D.; Zheng, C. Managing the Poverty- $\mathrm{CO}_{2}$ Reductions Paradox. Organ. Environ. 2015, $28,355-373$. [CrossRef]

42. Ozanne, L.K.; Phipps, M.; Weaver, T.; Carrington, M.; Luchs, M.; Catlin, J.; Gupta, S.; Santos, N.; Scott, K.; Williams, J. Managing the Tensions at the Intersection of the Triple Bottom Line: A Paradox Theory Approach to Sustainability Management. J. Public Policy Mark. 2016, 35, 249-261. [CrossRef]

43. Sarkis, J.; Zhu, Q.; Lai, K. An organizational theoretic review of green supply chain management literature. Int. J. Prod. Econ. 2011, 130, 1-15. [CrossRef]

44. Jabbour, A.B.; Jabbour, C.; Govindan, K.; Kannan, D.; Arantes, A.F. Mixed methodology to analyze the relationship between maturity of environmental management and the adoption of green supply chain management in Brazil. Resour. Conserv. Recycl. 2014, 92, 255-267. [CrossRef]

45. Yan, M.-R.; Chien, K.-M.; Yang, T.-N. Green component procurement collaboration for improving supply chain management in the high technology industries: A case study from the systems perspective. Sustainability 2016, 8, 105. [CrossRef]

46. Elkington, J. Partnerships from cannibals with forks: The triple bottom line of 21st-century business. Environ. Qual. Manag. 1998, 8, 37-51. [CrossRef]

47. Freeman, J.; Chen, T. Green supplier selection using an AHP-Entropy-TOPSIS framework. Supply Chain Manag. Int. J. 2015, 20, 327-340. [CrossRef]

48. Khalid, R.U.; Seuring, S.; Beske, P.; Land, A.; Yawar, S.A.; Wagner, R. Putting sustainable supply chain management into base of the pyramid research. Supply Chain Manag. Int. J. 2015, 20, 681-696. [CrossRef]

49. Saunders, M.N.K.; Lewis, P.; Thornhill, A. Research Methods for Business Students, 7th ed.; Pearson Education: New York, NY, USA, 2015; ISBN 978-0-273-75075-8.

50. Young, S.B. Responsible sourcing of metals: Certification approaches for conflict minerals and conflict-free metals. Int. J. Life Cycle Assess. 2015. [CrossRef]

51. Bleischwitz, R.; Dittrich, M.; Pierdicca, C. Coltan from Central Africa, international trade and implications for any certification. Resour. Policy 2012, 37, 19-29. [CrossRef]

52. Akemu, O.; Whiteman, G.; Kennedy, S. Social enterprise emergence from social movement activism: The Fairphone case. J. Manag. Stud. 2016, 53, 846-877. [CrossRef] 
53. Joshi, S.; Cerratto-Pargman, T. On fairness \& sustainability: Motivating change in the networked society. Adv. Comput. Sci. Res. 2015. [CrossRef]

54. Fairphone. About Us. Available online: https://www.fairphone.com/en/about/about-us/ (accessed on 29 December 2017).

55. Mayring, P. Qualitative Inhaltsanalyse: Grundlagen und Techniken, 11th ed.; Beltz: Weinheim, Germany, 2010; ISBN 978-3-407-29142-4.

56. Moran, D.; McBain, D.; Kanemoto, K.; Lenzen, M.; Geschke, A. Global Supply Chains of Coltan. J. Ind. Ecol. 2015, 19, 357-365. [CrossRef]

57. Fairphone. Research Trip: Visiting Tin, Tantalum and Tungsten Mines. Available online: https:/ /www.fairphone. com/de/2014/10/02/research-trip-visiting-tin-tantalum-and-tungsten-mines / (accessed on 29 December 2017).

58. Fairphone. Our Latest Step to Integrate Conflict-Free Tungsten Visiting the Mine in Rwanda. Available online: https: / / www.fairphone.com/de/2016/03/19/our-latest-step-to-integrate-conflict-free-tungsten/ (accessed on 29 December 2017).

59. Pagell, M.; Wu, Z. Building a more complete theory of sustainable supply chain management using case studies of 10 exemplars. J. Supply Chain Manag. 2009, 45, 37-56. [CrossRef]

60. Fairphone. On-Site Visit to Cobalt Mines in Congo. April 2017. Available online: https:/ /www.fairphone. com/de/2017/06/07/on-site-visit-to-cobalt-mines-in-congo-april-2017/ (accessed on 29 December 2017).

61. Khor, K.S.; Udin, Z.M. Reverse logistics in Malaysia: Investigating the effect of green product design and resource commitment. Resour. Conserv. Recycl. 2009, 81, 71-80. [CrossRef]

62. Wilts, H.; Bringezu, S.; Bleischwitz, R.; Lucas, R.; Wittmer, D. Challenges of metal recycling and an international covenant as possible instrument of a globally extended producer responsibility. Waste Manag. Res. 2011, 29, 902-910. [CrossRef] [PubMed]

63. Fairphone. A European Program for Returning Used Phones. Available online: https://www.fairphone. com/de/recycling-program/ (accessed on 30 March 2017).

64. Ting, M.H.; Seaman, J. Rare Earths: Future Elements of Conflict in Asia? Asian Stud. Rev. 2013, 37, $234-252$. [CrossRef]

65. Fairphone. Progress and Challenges to Improving Working Conditions with Our Fairphone 2 Manufacturer. Available online: https:/ / www.fairphone.com/de/2016/08/18/progress-challenges-improving-workingconditions-fairphone-2-manufacturer/ (accessed on 29 December 2017).

66. Fairphone. Cost Breakdown of the Fairphone 2. Available online: https://www.fairphone.com/de/2015/ 09/09/ cost-breakdown-of-the-fairphone-2/ (accessed on 29 December 2017).

67. Fairphone. Fairphone 2 Supply Chain on Sourcemap. Available online: http://free.sourcemap.com/view/10617 (accessed on 30 March 2017).

68. Garcia-Torres, S.; Rey-Garcia, M.; Albareda-Vivo, L. Effective Disclosure in the Fast-Fashion Industry: From Sustainability Reporting to Action. Sustainability 2017, 9, 2256. [CrossRef]

69. Smith Stegen, K. Heavy rare earths, permanent magnets, and renewable energies: An imminent crisis. Energy Policy 2015, 79, 1-8. [CrossRef]

(c) 2018 by the authors. Licensee MDPI, Basel, Switzerland. This article is an open access article distributed under the terms and conditions of the Creative Commons Attribution (CC BY) license (http:/ / creativecommons.org/licenses/by/4.0/). 